\title{
Special issue of Dairy Science \& Technology The Eighth Cheese Symposium-Moorepark 2011
}

\author{
Kieran N. Kilcawley
}

Received: 24 July 2012 / Accepted: 24 July 2012 / Published online: 4 October 2012

(C) INRA and Springer-Verlag, France 2012

This special issue contains a number of presentations given at The Eighth Cheese Symposium held in Cork on 28th and 29th September 2011. The symposium has continued an established tradition which began in 1988 of disseminating cheese research and providing a forum for researchers and industry. It is also a valuable opportunity for participants to meet and discuss pertinent issues relating to cheese. All previous symposia were jointly organised by Teagasc and University College Cork. In 2011, for the first time, this Eighth Cheese Symposium also involved collaboration with INRA, the French National Institute for Agricultural Research.

The themes of the symposium were: cheese flavour development, cheese diversification, health and nutrition/fat and salt reduction and cheese: from quality to concepts. Over 170 delegates attended from 14 countries and were equally represented by industry and academia. There were 30 oral and 60 poster presentations, which were all of a very high calibre, highlighting the diversity and depth of current international cheese research. One aspect of the symposium which was prominent throughout and is worth specifically mentioning was the quality of work and presentations by students. This special issue of Dairy Science \& Technology contains two reviews and nine research papers presented at the symposium. I would like to thank the authors, reviewers and editors who have helped in its successful publication. I hope that you value this special issue of Dairy Science \& Technology as much as I do.

The Eighth Cheese Symposium was a huge success with very positive feedback from participants. I am already looking forward to the Ninth Cheese Symposium which will be held for the first time in France. The success of the symposium required a lot of commitment and hardwork, and therefore, I would like to thank all the members of the scientific and organising committees, the sponsors, Teagasc, UCC and INRA. A particular mention has to go both Ms. Niamh O'Brien and Dr. John Hannon at the Teagasc Food Research Centre in Moorepark, who ensured that the symposium ran as smoothly as planned.

K. N. Kilcawley $(\bowtie)$

Moorepark, Teagasc Food Research Centre, Fermoy Co., Cork, Ireland e-mail: kieran.kilcawley@teagasc.ie
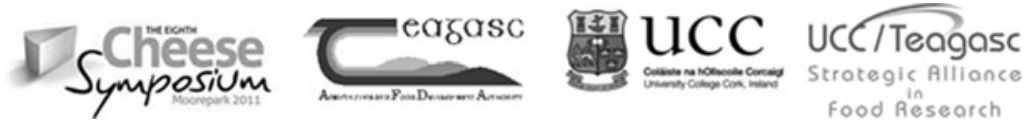